\section{Formação de professores no contexto online: concepções propiciadas pela escrita sobre o estágio docência}

\author{
Teacher training in the online context: \\ conceptions provided by writing about the \\ teaching internship \\ Anahy Arrieche Fazio ${ }^{1}$
}

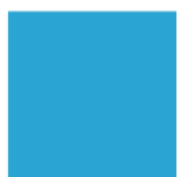

Revista Extensão em Foco

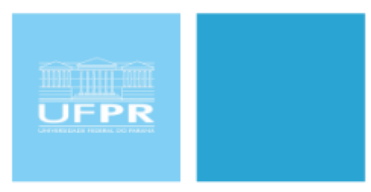

ISSN $2358-7180$

\title{
RESUMO
}

Esse artigo registra o processo formativo constituído pela autora através da leitura e escrita de cartas durante a participação no Cirandar: rodas de investigação na escola - 2020-21, edição online. As cartas que constituem esse artigo comunicam o processo formativo de uma professora-tutora motivada a pensar e repensar aspectos teórico-práticos da formação e constituição docente, partindo de suas experiências no contexto online do curso de Licenciatura em Ciências EaD da FURG. Busca-se compreender sobre a formação docente a partir da escrita das memórias nos estágios docência, tanto na posição de estagiária como de orientadora de estágio. $\mathrm{O}$ artigo está organizado em três cartas: a primeira objetiva a apresentação da pesquisadora; a segunda comunica sua intenção de pesquisa e a terceira registra suas conclusões e compreensões. Do processo, conclui-se que a formação de professores em contextos online deve buscar metodologias que valorem a dialogicidade, interdisciplinaridade, contextualização e a escrita em diferentes momentos do percurso formativo docente.

Palavras-chave: Formação de Professores. Estágio Docência. Online.

\section{ABSTRACT}

This article records the formative process constituted by the author through the reading and writing of letters while participating in Cirandar: research circles at school - 2020-21, online edition. The letters expressed on this article communicate the training process of a teacher-tutor motivated to think and rethink theoretical and practical aspects of teacher training and constitution, starting from her experiences in the context of the Bachelor of Science course, in distance education at FURG. It seeks to understand about teacher education from the writing of memories in the teaching internships, in the position of intern and as an internship supervisor. The article is organized in three letters: the first aims at the presentation of the researcher; the second communicates its intention to research and the third registers its activities and scope. From the process, it is concluded that the training of teachers in online contexts must seek methodologies that value dialogicity, interdisciplinarity, contextualization and writing at different moments of the teacher training path.

Keywords: Teacher Training. Teaching Internship. Online.

\footnotetext{
${ }^{1}$ Doutoranda no Programa de Pós-Graduação em Educação em Ciências. Universidade Federal do Rio Grande (FURG), Rio Grande, Rio Grande do Sul, Brasil. E-mail: anahyfazio@yahoo.com.br. Orcid: https://orcid.org/0000-0003-4067-7983
} 


\section{Introdução}

Nesse artigo, comunico os significados construídos durante a participação no Cirandar: rodas de investigação na escola - 2020-21, online, onde a escrita e leitura de cartas fomentaram os diálogos entre seus participantes. O artigo apresenta as três cartas produzidas. A primeira objetiva apresentar a pesquisadora, a segunda comunicando sua intenção de pesquisa e a terceira registrando as compreensões decorrentes dos estudos realizados.

As cartas comunicam o processo formativo de uma professora-tutora motivada a pensar e repensar aspectos teórico-práticos de sua formação e constituição docente a partir da escrita de suas memórias sobre o estágio docência, tanto na posição de estagiária do curso de Licenciatura em Física da FURG quanto de orientadora de estágio no Curso de Licenciatura em Ciências EaD da mesma universidade.

\section{CARTA 1 - Quem sou eu?}

Rio Grande, 20 de setembro de 2020

Olá todos, todas e todes, espero que estejam bem! Afinal, nos últimos meses esse é o desejo mais pungente em cada um de nós, não?

Moro em Rio Grande e sou professora de Física licenciada pela FURG. Nessa mesma universidade, tornei-me mestre em Ciências Fisiológicas e doutoranda do Programa de Pós-Graduação em Ciências. Profissionalmente, fui professora do estado do RS durante 4 anos e sou tutora do curso de Licenciatura em Ciências EaD da FURG há 6 anos, inclusive, estar atuante nesse curso foi um dos motivos que me trouxe ao doutorado e a posição de membro da comissão organizadora do Cirandar. Pontuo como um dos motivos porque enquanto professora da escola tive o prazer de compor um grupo da área da Ciências da Natureza onde um dos professores participa do Cirandar e de sua organização desde seu princípio, o professor Cezar Motta, então, ainda que não participando naquela época, por tornar-me amiga desse professor, acompanhei o processo formativo durante os 4 anos em que estivemos trabalhando juntos.

Me considerei, por muito tempo, uma cética das potencialidades da relação universidade-escola. Esse ceticismo, origina-se com meu movimento como professora da escola e com todos os desafios pedagógicos que encontrei, me mostrando que essas formações verticais, isto é, a FURG detentora do saber chega na escola querendo 
ENSINAR os professores, não funcionavam. Caso contrário, a educação já teria mudado e o cenário que eu encontraria enquanto professora seria muito diferente daquele que encontrei nos meus primeiros anos da universidade, 8 anos antes. E isso não ocorreu.

O que mudou? Como fui parar no Cirandar?

Estar professora do estado e participar do curso de Licenciatura em Ciências me oportunizaram estar em coletivo. Sim, coletivos de professores que compartilhavam ideias, experiências, criatividade e angústias para que juntos pudessem repensar seus princípios teórico-práticos. Apesar do curso de licenciatura contar com professores formadores, o professor-tutor é membro atuante nas tomadas de decisões acerca do curso. Paralelamente, atuando na escola, compunha outro coletivo de professores que buscava formas de desenvolver projetos colaborativos e investigativos na área de Ciências da Natureza. Estar nesses coletivos me fez perceber a importância desse conhecimento, conhecimento construído na troca que supera as "demagogias" e "teorização" pura com a qual sempre associei o campo da educação. Logo, reencontro no curso de ciências a professora Maria do Carmo que me estimula a ingressar no doutorado, não somente ela, mas também o professor Valmir, o professor Cezar e meu amigo de anos professor Charles. No doutorado, ingresso com meu olhar para a escola, mas acabo voltando-me ao curso de Ciências. Também passo a fazer parte do grupo Comunidade de Indagação em Ensino de Física Interdisciplinar (CIEFI) e representante do grupo na equipe organizadora do Cirandar, já que o grupo CIEFI é um dos parceiros do Cirandar.

Estar no CIRANDAR é um grande orgulho. Ele expressa algumas das minhas crenças em torno do que é ser professor e também me ensina o que é uma formação horizontal: eu aprendo com você e você comigo, não importa sua posição hierárquica, apenas a sua experiência e o que ela irá nos possibilitar aprender.

Acreditem ou não, fiz um "resumo" de quem sou e como cheguei aqui. E isso que ainda nem coloquei no balanço meu "novo ser" proveniente do momento de pandemia. Vou deixa-lo para as reflexões da minha próxima carta.

Agradeço a atenção de vocês desde já.

Anahy Arrieche Fazio 
CARTA 2 - Como me encontro com minha temática de estudo no Cirandar 2020?

Rio Grande, 27 de setembro de 2020

Boa tarde, colegas de Ciranda!

Como comentei com vocês no nosso último encontro síncrono, estava com bastante dúvida sobre o que iria escrever. Penso que esse período em casa, com uma nova rotina pessoal e de estudos, nos faz refletir sobre outros aspectos da nossa história.

Ano passado, meu relato do cirandar voltou-se à argumentação. Inclusive, fora esse relato que enviei para outra roda que participo, do Encontro de Investigação na Escola. Fiquei feliz com os feedbacks positivos que estou recebendo e o quanto contar sobre a minha experiência afeta as outras pessoas e as fazem pensar sobre as suas próprias vivências. No relato, reflito sobre o papel do tutor na construção de argumentos por parte dos estudantes em relação aos fenômenos e situações que são postas durante o curso de Licenciatura em Ciências. Também reflito sobre a formação inicial desses discentes e também sobre a formação continuada do professor-tutor. Conclui que as ferramentas online propiciam espaços de interação entre os participantes do curso e também destes com os artefatos disponibilizados e que através da indagação e diálogo os estudantes são capazes de formar argumentos acerca dos fenômenos postos.

A partir dessa vivência e da participação na disciplina de interdisciplinaridade, da pós-graduação, começo a pensar sobre a importância de momentos que nos permitam conhecer, ouvir, ler o que o outro produz e ao mesmo tempo visitarmos nossas memórias e escritas. Escrever sobre essas experiências, inclusive, me fazem pensar sobre o papel da escrita reflexiva na minha formação, ainda que escrever seja um desafio para nós das exatas.

Fazenda (1995) enfatiza a importância do registro das experiências e também afirma que o movimento dialético na abordagem interdisciplinar está no dialogar com as nossas próprias produções, sempre buscando novas revelações e pressupostos. Assim, percebo esse Cirandar 2020 como mais um momento de revisitar e registrar uma experiência do Licenciatura em Ciências, almejando uma escrita reflexiva, afinal, como Fazenda (1991) aponta, a atitude interdisciplinar é uma atitude para conhecer mais e 
melhor sobre algo e impele o diálogo, seja com pares idênticos, anônimos, consigo. É uma atitude de desafio, envolvimento e comprometimento.

O curso de Licenciatura em Ciências EaD é interdisciplinar e pressupõe, tanto no seu Projeto Pedagógico do Curso (PPC) quanto nas escritas e estudos que antecederam sua criação, um caráter interdisciplinar, coletivo e dialógico. Moraes (2011) registram em artigo o resultado de uma formação de professores que viriam a fazer parte do curso de Ciências, professores que hoje atuam nesse curso e que auxiliaram/auxiliam na sua formação. Nesse artigo, afirmam que:

Quando os participantes de uma formação em EAD compreendem os espaços formativos como comunidades aprendentes, com os professores assumindo papel decisivo de mediação a partir do que já conhecem, criam-se oportunidades de ensinar também o que os professores e os tutores, não sabem. (p.18)

Essa quarentena me fez refletir muito sobre aquilo que eu não sabia e hoje sei. Aquilo que a experiência no ciências, de estar em comunidade somado a minha atitude interdisciplinar me fizeram refletir, retornar a mim mesma, e aprender algo novo. A experiência como tutora me fez mudar a minha forma de conduzir minhas aulas presenciais, passei a ser mais receptiva, ouvir mais, indagar mais, além de levar para as aulas de física ferramentas e metodologias que via sendo aplicadas nas nossas aulas dos ciências. Certamente, a experiência como orientadora de estágio é grande responsável por essa mudança.

Não é à toa que o ciências me trouxe ao doutoramento, lugar onde aprendi tanto sobre a pesquisa em Ciências e também sobre metodologias, autores, referenciais teóricos e até sobre o poder da escrita, principalmente as reflexivas. De maneira indireta, estar professora-tutora foi o que me trouxe até aqui: mais um espaço para que eu possa exercer minha atitude interdisciplinar a partir do viver com o outro e pensar sobre a importância de registrar, na escrita, essas experiências.

A pandemia nos convida a conhecer mais sobre as ferramentas online de ensino, uma vez que estudantes e professores, das diferentes modalidades, desafiaram-se no ensino de forma remota, fazendo uso dos mais diferentes artefatos. Considero que estar tutora em um curso de licenciatura a distância, me agrega de conhecimento de aspectos teórico-práticos em torno do ensino online. Assim, revisito minhas memórias desses 6 anos de atuação enquanto tutora e começo a refletir sobre um momento específico que é muito desafiador para todo professor em formação: estágio docência. Se esse momento 
já é desafiador no ensino presencial, como que esse momento é compreendido em um curso a distância? Como o tutor, formado na modalidade presencial, compreende o papel de supervisor de estágio? Como essas vivências e registros podem contribuir para amenizar os desafios impostos pela pandemia? Como a escrita e o registro contribuem para pensar sobre esses momentos formativos?

Anahy Arrieche Fazio

\section{CARTA 3 - Os estágios da minha vida: Onde tudo começou?²}

Minha memória nos leva ao ano de 2010, quando então estudante de Física Licenciatura na FURG, inicio meu estágio docência. Compreendi o estágio como um momento de desafio. Experienciar, pela primeira vez, a regência de classe exigia muito de estudantes cujas referências de sala de aula de Física, até então, eram seus professores formadores. Professores estes que conduziam aulas tradicionais, pautadas na matemática, com aulas expositivas, avaliações densas, descontextualizadas e completamente disciplinares. Um dos maiores exemplos da falta de contexto eram as atividades experimentais. Nessas aulas, costumávamos reproduzir experimentos das "cartilhas" em um procedimento quase mecânico de obtenção de resultados, os quais não compreendíamos, não conseguíamos associar a outros contextos da Física e tão pouco com a nossa realidade. Resta-me, quase dez anos depois, a pergunta: que experiência eram/é essa do ser professor de Física antes dos estágios e depois dos estágios?

Machado e Bierhalz, 2019, apontam que por mais que os alunos tenham contato com as escolas e com a realidade escolar, essa experiência é na posição de aluno, estar responsável pelo conteúdo, aprendizagem e pela turma é um processo complexo. Mas, a partir de seus estudos, concluem que é nessa experiência que o licenciando pode se identificar ou não com as situações da sala de aula, testando suas crenças, modelos e percepções (MACHADO E BIERHALZ, 2019).

Durante meu estágio pude contar com a experiência dos professores orientadores, universidade e escola, e assim, desenvolvemos coletivamente meu planejamento de

\footnotetext{
2 Escrita posteriormente publicada em: FAZIO, A.A.; PIREZ, D.R.M.; RUAS, F. P. Memórias Interdisciplinares no ensino de Ciências/Física. In: ARAUJO, R.R.; MARTINEZ M.L.S. (org.). Sonhos e rizomas: memórias e metáforas de um coletivo interdisciplinar [ Recurso eletrônico ]. Porto Alegre: Mundo Acadêmico, 2021, p.80 - 95.
} 
estágio. Decidimos desenvolver as atividades de estágio a partir de uma proposta interdisciplinar pautada no contexto do município de Rio Grande, logo, o planejamento de estágio fora intitulado "A Revolução Industrial e Física: A Energia que Movimenta o Mundo" e considerava a presença de uma refinaria nas proximidades da escola e também o fato de a cidade ser repleta de trilhos férreos, que outrora movimentavam o comércio e o transporte de pessoas e perecíveis na cidade.

Neste projeto, trabalhamos a temática de calor e usos de energia, utilizando-se de diversas metodologias, incluindo atividades experimentais, uso de simuladores computacionais, aulas expositivas com o uso de multimídia, jogos e a construção de um blog, "Silva Paes Ciência" com o propósito de discutirmos temáticas paralelas que complementavam a prática pedagógica e fomentava a escrita, leitura e debate entre os estudantes. A partir dessa experiência, em Fazio, Heckler e Santos (2010) concluímos que o estágio e a experiência docente possibilitaram observar que estudantes considerados desmotivados, reclusos, tornaram-se participativos e dialógicos, construindo argumentos a partir das atividades propostas. Em relação ao estágio docência, concluímos que a universidade precisa estar engajada na formação docente e oportunizar: vivência no contexto escolar e espaço de reflexão acerca das aprendizagens teórica e práticas. Para além da reflexão, o estágio pode ser considerado como um espaço de produção do conhecimento acerca do ensinar e aprender (MIRANDA, 2018).

Em 2014, tenho uma nova experiência formativa e passo a integrar a equipe do curso de Licenciatura em Ciências EaD da FURG na posição de professora-tutora a distância, e assim, em 2017 retorno aos estágios supervisionados na posição de professora orientadora no curso. Esse curso é organizado de forma interdisciplinar, no entanto, para que isso ocorra, é preciso consonância entre os aspectos teóricos e práticos, transpor a ideia da interdisciplinaridade como a soma de disciplinas. Moraes (2011) registram em artigo o resultado de uma formação de professores que viriam a fazer parte do curso de ciências, professores que hoje atuam nesse curso e que auxiliaram/auxiliam na sua formação.

Como já relatei na carta anterior, estar em comunidade somado a minha atitude interdisciplinar me fizeram refletir, retornar a mim mesma, e aprender algo novo. Mudei minha forma de conduzir minhas aulas presenciais, passei a ser mais receptiva, ouvir mais, indagar mais, além de levar para as aulas de Física ferramentas e metodologias que via sendo aplicadas nas nossas aulas assíncronas do curso de licenciatura em ciências, 
inclusive, atividades experimentais. Ressalvo o reencontro com os registros escritos, cuja ênfase e importância já tinha reconhecido na proposição do blog durante meu estágio docência, mas que pouco exercia durante minha prática profissional.

Essa mudança emerge do fato de que na educação a distância, os processos de ensino e aprendizagem são mediados por ambientes virtuais, possibilitados pelas Tecnologias de Informação e Comunicação, e nesse espaço de formação emergem diferentes modos de relação entre seus diferentes atores: estudantes, professores e tutores. Assim, a compreensão de novos conteúdos, metodologias acontece no diálogo com e entre esses saberes e sujeitos (ZANOTTO et al., 2017).

Acerca das orientações de estágio na $\mathrm{EaD}$, estas funcionavam da mesma maneira que no ensino presencial, isto é, os estudantes nos encaminham seus planos de aula com uma semana de antecedência da data de aplicação daquela aula e sugerimos modificações, todo esse processo acontece de forma assíncrona via Ambiente Virtual de Aprendizagem Moodle (AVA-MOODLE). Exercer o papel de orientadora foi muito importante, uma nova experiência em um novo desafio. Dessa vez, eu orientava os estudantes e dava dicas de como é "agir" professor a partir de todas as minhas experiências como professora.

Esse trocar de experiências é propiciado pelas ferramentas AVA Moodle, acontecendo durante fóruns, feedbacks dos planejamentos de estágio e atividades, conversas via Moodle e até webconferências, prioritariamente utilizando a linguagem escrita. Nessas interações, quando o orientador problematiza os planejamentos, indagando acerca das ações e como elas se adaptam ao contexto e aos conhecimentos teóricos, os estudantes se transformam e, ao invés de apenas reproduzir os conhecimentos teóricos e metodológicos, passam a se compreenderem como protagonistas, capazes de organizarem e coordenarem diversas situações de sala de aula a partir de sequências didáticas, projetos experimentais, unidades de aprendizagem e outros estratégias para conduzir suas aulas (PETRUCCI, MEDEIROS E SHIMABUKURU, 2001).

Durante as supervisões estive em salas lotadas de crianças enérgicas, sentei em rodas, fiz atividade experimental, participei de jogos, fui elogiada, convencida por alunos a "aprovarem" suas amadas estagiárias. Observei estagiárias dispostas a enfrentar o "caos" de aulas onde os estudantes podiam discutir conteúdos livremente, realizarem jogos e brincadeiras. Me marcaram momentos de diálogo e o bolo que comemos no 
refeitório de uma escola do campo onde a estagiária levou um microscópio para os estudantes olharem os insetos.

Durante o curso, foram propostas várias atividades experimentais em projetos investigativos que propiciassem a reflexão sobre o fenômeno observado a partir da indagação e da interação entre os estudantes. Essas atividades investigativas foram fundamentais para que os discentes compreendessem a importância de realizar projetos investigativos nas escolas, em uma perspectiva interdisciplinar, onde seus futuros alunos pudessem compreender um fenômeno da sua realidade a partir da interação com uma atividade e entre si (HECKLER, FAZIO E RUAS, 2020). Em relação às atividades experimentais, me recordo de uma aula onde assisti a estagiária construir um modelo atômico com seus alunos, sempre os indagando e incentivando a trabalharem em grupos.

O que essas experiências me ensinaram? Que o curso de Licenciatura em Ciências pode ser considerado um espaço formativo de todos os sujeitos que neles estão, onde os conhecimentos teórico-práticos são construídos na coletividade, sendo o estudante um coautor do seu processo formativo (FAZIO, HECKLER E GALIAZZI, 2020). Percebo que a prática é apreendida no viver, no perguntar, no descobrir, em observar fenômenos e buscar explicá-los em sua completude, sem disciplinar ou segmentar. Em recente trabalho, Machado e Bierhalz, 2019, apontam que a interdisciplinaridade é um reflexo dos desafios da sociedade contemporânea, já que exige discussões que superem a fragmentação de análise dos fenômenos. Portanto, nos cursos de formação de professores ela é expressa nas concepções que motivam projetos pedagógicos, práticas pedagógicas que envolvem diferentes componentes curriculares.

O que estudar sobre o estágio docência durante o Cirandar 2020-21 me permitiu concluir sobre a docência?

Minhas experiências como professora-tutora me fizeram e fazem repensar acerca de alguns fatores, no que tange o ensino de Física e Ciências:

1) É preciso propostas metodológicas que estejam atreladas a realidade do aluno, em toda a sua pluralidade, intendendo a interdisciplinaridade como um meio para a compreensão dessa realidade. 
2) Deve haver dinamismo de metodologias e o uso dos artefatos tecnológicos que propiciam espaço de diálogo entre os estudantes e os professores, em todos os níveis de formação.

3) Deve se assumir um caráter investigativo, dialógico e problematizador ao desenvolver atividades experimentais. Essas, devem auxiliar o estudante a investigar problemas e desafios do seu cotidiano, servirem de meio para um fim.

4) A formação presencial de professores deve se espelhar nas metodologias empregadas na $\mathrm{EaD}$, aproximando formadores de seus estudantes e incentivando que eles sejam os protagonistas do seu conhecimento.

\section{CONSIDERAÇÕES FINAIS}

No processo de releitura das cartas para sistematiza-las e comunica-la nesse artigo, percebo o registro de um rico processo investigativo. No movimento da escrita das memórias em cartas, muitas indagações emergem e são compreendidas durante o processo, embora não todas.

Além de participante, pude atuar como coordenadora de uma das rodas de diálogo online constituídas durante o processo formativo. Dessa experiência em roda, da interlocução e diálogo por intermédio de cartas, pude delimitando minha temática de pesquisa e compreendendo, a partir dos estudos compartilhados nas cartas de meus colegas, diferentes aspectos sobre o processo de ser professora-tutora em um curso de licenciatura na modalidade a distância. Essa modalidade é possibilitada pelo contexto online, assim como o desenvolvimento do processo formativo do Cirandar 2020-21 e as aulas remotas que muitos professores estão ministrando durante o distanciamento social físico imposto pela pandemia do Corona vírus.

Nesse sentido, além das conclusões expostas na última carta que escrevi, acrescento a importância do registro no processo formativo de professores. Concluo que a formação em pares, dialógica e carregada de afetividade é expressa nas trocas e registros escritos e fotográficos na forma de cartas. Essa escrita, configura também importante artefato para a comunicação nas salas de aula remotas, como forma de proporcionar e perpetuar a construção de significados em pares. 
Por fim, a escrita também fomenta outras formas de expressões culturais. Compartilho o registro em vídeo, construído pela nossa roda de conversa, que expressa o que significou o Cirandar para nós, evidenciando a importância das escritas e leituras de cartas. Link: https://studio.youtube.com/video/L_mYkY5ac6o/edit

\section{REFERÊNCIAS}

FAZENDA, I. C.A. Interdisciplinaridade: História, teoria e pesquisa. 2a ed., São Paulo: Papirus, 1995

FAZENDA, I. C. A. Interdisciplinaridade: um projeto em parceria. São Paulo: Edições Loyola, 1991.

FAZIO, A.F.; HECKLER, V. GALIAZZI, M.C. Formação continuada: discussão e reflexão sobre a prática do professor tutor. In: SANTOS, A.B.; MACHADO, R.B; COLVERO, R.B (org.). Pesquisa e Sociedade: desafios e possibilidades. Pelotas: BasiBooks, 2020, p. 484-496.

FAZIO, A. F. ; OLIVEIRA, A.P.P.; HECKLER, V. Prática Docente no Ensino de Física: campo investigativo oportunizado pelo estágio supervisionado. In: XIX Congresso de Iniciação Científica - IX Mostra de Produção Universitária FURG. 2010. Rio Grande. Disponível em: https://propesp.furg.br/anaismpu/cd2010/cic.html. Acesso em 4 dez. 2020

HECKLER, V.; FAZIO, A. A.; RUAS, F. P. Investigation with experimental practical activities in training geographically distant teachers. Journal of Research and Knowledge Spreading, v. 1, n. 1, 2020.

MACHADO, L.; BIERHALZ, C. D. K.. Implicações do estágio supervisionado na formação do professor de Ciências. RELACult-Revista Latino-Americana de Estudos em Cultura e Sociedade, v. 5, n. 4, 2019. 
MIRANDA, A. K. P. O estágio obrigatório na formação de professores, na modalidade a distância, da UFMS. In: ROCHA, P.G. (org.). 10 anos de Educação a Distância na UFMS: as experiências das licenciaturas. Porto Alegre, RS: Editora FI, 2018, p. 9-36.

MORAES, R. Reconstruções em interações na linguagem: aprendizagens pela pesquisa em de EAD. Em Teia| Revista de Educação Matemática e Tecnológica Iberoamericana, v. 2, n. 3, 2011.

PETRUCCI, M. I. F.; MEDEIROS, A. G.; SHIMABUKURO, E. K. H. Tutoria na formação de professores de ciências-um modelo pautado na racionalidade prática. Revista Brasileira de Pesquisa em Educação em Ciências, v. 1, n. 3, 2001.

ZANOTTO, L; SOMMERHALDER A.; NICOLIELO, M.E.; MARTINS, A. O. Interações Virtuais entre Tutores e Estudantes no Moodle: Processos Educativos em Contexto de Estágio na Educação InfantiL. Reflexão e Ação, v. 25, n. 1, p. 218-237, 2017.

UNIVERSIDADE FEDERAL DO RIO GRANDE. 2018. Curso de Licenciatura em Ciências-Rio Grande/RS. In: Projeto Pedagógico do Curso de Graduação a distância Licenciatura em Ciências/FURG

Recebido em: 24 de maio de 2021. Aceito em: 26 de maio de 2021. 